\title{
Avaliação de fontes magmáticas de séries shoshoníticas pós-colisionais com base na normalização pela Associação Shoshonítica de Lavras do Sul - aplicação de sliding normalization
}

\author{
Joaquim Daniel de Liz', Evandro Fernandes de Lima ${ }^{2}$ \& Lauro Valentim Stoll Nardi ${ }^{2}$
}

\begin{abstract}
Resumo A Associação Shoshonítica de Lavras do Sul (ASLS) está relacionada ao início do magmatismo alcalino pós-colisional do ciclo orogênico Brasiliano no sul do Brasil. Esta foi gerada pela fusão de um manto litosférico metassomatisado por uma subducção prévia. A ASLS representa uma série co-genética que evoluiu por cristalização fracionada, com grande variação em $\mathrm{SiO}_{2}$, sendo estas características favoráveis na aplicação da técnica de sliding normalization. Esta técnica possibilita a comparação química entre termos ácidos, intermediários e básicos e a avaliação de tipos de fontes magmáticas, ambientes tectônicos e processos geradores. Utilizou-se como fator de normalização os valores obtidos na ASLS para cinco unidades shoshoníticas geradas em ambiente pós-colisional: o Plúton Tismana da Romênia, as rochas vulcânicas do norte do Platô do Tibet, o Domo Tormes da zona Central Ibérica, as rochas intrusivas shoshoníticas do pós-colisional Svecofenniano no sul da Finlândia e República da Carélia e o Quartzo-monzonito Baranadag da Turquia. Este procedimento estabeleceu a vinculação das fontes geradoras dos magmas dessas associações identificando-se duas tendências geoquímicas distintas. Uma caracterizada pelo enriquecimento em $\mathrm{Zr}, \mathrm{Nb}, \mathrm{TiO}_{2}, \mathrm{Y}$ e ETR, e outra marcada principalmente pelo aumento dos conteúdos de $\mathrm{Rb}$ e $\mathrm{K}_{2} \mathrm{O}$ e pelo decréscimo de $\mathrm{Nb}$. Os aumentos dos conteúdos de $\mathrm{Nb}$ expressam razoavelmente a participação de magmas astenosféricos, enquanto que o enriquecimento em $\mathrm{K}_{2} \mathrm{O}$ e $\mathrm{Rb}$ indica assimilação crustal. $\mathrm{O}$ diagrama triangular $\mathrm{Nb}-\mathrm{Rb}-\mathrm{K}_{2} \mathrm{O}$ normalizado pela ASLS é proposto para rochas shoshoníticas pós-colisionais, como uma ferramenta na separação de associações que envolveram assimilação crustal daquelas com a adição de magmas astenosféricos.
\end{abstract}

Palavras-chave: rochas shoshoníticas, pós-colisional, sliding normalization, fontes magmáticas.

\begin{abstract}
Investigation of the magmatic sources of post-collisional shoshonitic series based upon the sliding normalization technique using the Lavras do Sul Shoshonitic Association as the normalization pattern. The Lavras do Sul Shoshonitic Association is related to the early stages of post-collisional alkaline magmatism in the Brasiliano Orogenic Cycle in southern Brazil. Their magmas were produced through melting of a litospheric mantle metasomatized during a previous subduction. The LSSA is composed of co-genetic rocks derived from magmas evolved by fractional crystallization which show a large silica range. These features are quite adequate for interpretations based on the sliding normalization technique, which allows comparing magmas with different degrees of differentiation in order to evaluate and discuss their potential sources, petrogenetic mechanisms and geotectonic settings. The LSSA composition was used as the pattern for normalizing data available in bibliography for the Late Precambrian post-collisional Tismana pluton, the $1.8 \mathrm{Ga}$ Svecofennian post-collisional shoshonitic magmatism in the Fennoscandian shield, the monzonitic series from the Variscan Tormes Dome, the post-collisional potassic and ultrapotassic magmatism in northern Tibet, and the Baranadag pluton in Central Anatolia, Turkey. This procedure allowed the identification of two distinct geochemical trends: (i) Zr-Nb-Ti-Y-REE enrichment, and (ii) increasing of $\mathrm{Rb}-\mathrm{K}_{2} \mathrm{O}$ with concomitant $\mathrm{Nb}$ decrease. The former probably reflect the participation of an astenospheric component, whilst the second trend is related to crustal assimilation. The $\mathrm{Nb}-\mathrm{Rb}-\mathrm{K}_{2} \mathrm{O}$ diagram, used for values normalized by this technique, is proposed for discriminating post-collisional shoshonitic associations with different contributions of astenospheric and crustal materials.
\end{abstract}

Keywords: shoshonitic associations, post-collisional magmatism, sliding normalization, magmatic sources.

INTRODUÇÃO As pesquisas sobre rochas magmáticas fundamentadas na associação de dados de campo, petrográficos, químicos e experimentais auxiliam na construção de hipóteses que reúnam as características químicas do magmatismo, os aspectos evolutivos e os ambientes de formação. Estas investigações permitiram consolidar os parâmetros referentes as séries magmáticas com base nas características mineralógicas e químicas comuns e estabelecer relações geográfica e temporal entre os diferentes tipos de rochas e os ambientes tectônicos.

1 - Universidade Federal do Rio Grande do Sul - UFRGS, Instituto de Geociências, Programa de Pós-Graduação, Porto Alegre (RS), Brasil. E-mail: jdanielliz@yahoo.com.br

2 - Universidade Federal do Rio Grande do Sul - UFRGS, Instituto de Geociências, Programa de Pós-Graduação, Porto Alegre (RS), Brasil. E-mails: evandro.lima@ufrgs.br; lauro.nardi@ufrgs.br 
Uma das limitações no estudo geoquímico das séries magmáticas é a comparação entre rochas com diferentes graus de diferenciação. Esta dificuldade surge especialmente na modificação dos teores de elementos maiores e traços decorrentes dos processos magmáticos evolutivos, envolvendo principalmente a cristalização fracionada (Wilson 1993). Considerando os teores de $\mathrm{SiO}_{2}$ como índice de diferenciação os monzonitos no diagrama TAS de classificação das rochas plutônicas (Middlemost 1994) abrangem um intervalo de $53 \%$ até $69 \%$, podendo estes teores ser ainda mais amplos no diagrama R1R2 (De la Roche et al. 1980), o que dificulta uma comparação química confiável entre os termos.

Uma proposta para auxiliar na comparação de séries magmáticas foi elaborada por Liégeois et al. (1998), denominada de sliding normalization. Esta ferramenta auxilia na comparação química de termos ácidos a básicos ressaltando diferenças de fonte e de processos de fracionamento.

A partir da proposta por Liégeois et al. (1998), foram selecionadas amostras da Associação Shoshonítica de Lavras do Sul (ASLS) para a aplicação da técnica de sliding normalization, com o objetivo de comparar o magmatismo pós-colisional de afinidade shoshonítica dessa região com outros grupos de rochas de mesma afinidade geradas também em ambiente pós-colisional.

\section{SÉRIES SHOSHONÍTICAS PÓS-COLISIONAIS}

O pós-colisional é definido como o evento que sucede a colisão (Harris et al. 1986; Liégeois 1998; Bonin et al 1998), ou seja, o início do pós-colisional ocorre após o pico do metamorfismo representado pelo último estágio compressional da orogenia. Este período é complexo, sendo marcado por grandes movimentos horizontais de blocos ao longo de grandes zonas de cisalhamento, podendo ocorrer delaminação de litosfera, subducção de pequenas placas oceânicas e geração de rift. O magmatismo no pós-colisional é representado principalmente pela formação de grandes batólitos com afinidade dominantemente cálcio-alcalina alto-K com rochas shoshoníticas subordinadas (Liégeois 1998; Harris et al. 1986), podendo ocorrer esporádicos granitóides com afinidade alcalina a peralcalina e peraluminosos.

Estudos petrogenéticos no magmatismo gerado no evento pós-colisional não somente demonstra contrastes nos processos geodinâmicos responsáveis pelo fim do evento colisional e pelo começo do colapso extensional, mas também revela mudanças nas fontes dos magmas relacionadas a esses processos. É típico do magmatismo gerado no evento pós-colisional as assinaturas geoquímicas relacionadas a subducção, apesar dos processos de subducção terem cessado com a colisão continental. As assinaturas relacionadas à subducção são atribuídas ao metassomatismo do manto litosférico por fluidos derivados da placa subductada antes da colisão (Pearce et al. 1990; Turner et al. 1992, 1993, 1996; Platt \& England 1993).

No presente trabalho define-se como rochas da série shoshonítica aquelas que ocupam no diagrama QAPF (Streckeisen 1976) os campos dos gabros, dio- ritos, monzodioritos, monzonitos, quartzomonzonitos e granitos, ou seus correspondentes vulcânicos, definindo o denominado trend latítico (Tauson 1983). Os basaltos possuem fenocristais de olivina, augita-diopsídio e óxidos de Fe e Ti. Os termos intermediários são comumente ricos em plagioclásio. No diagrama TAS (Le Bas et al. 1986) elas distribuem-se ao longo dos campos das rochas alcalinas saturadas em sílica, cumprindo no entanto a condição $\left(\mathrm{K}_{2} \mathrm{O}+2\right)>\mathrm{Na}_{2} \mathrm{O}$ e $\mathrm{K}_{2} \mathrm{O} \backslash \mathrm{Na}_{2} \mathrm{O}<2,0$ e sendo denominadas quando extrusivas traquibasaltos potássicos, shoshonitos e latitos, além dos traquitos e riolitos. De acordo com o critério sugerido por Peacock (1931) elas são álcali-cálcicas e de acordo com os parâmetros de Shand são geralmente metaluminosas. A abundância em $\mathrm{Sr}, \mathrm{Ba}, \mathrm{Rb}$ e outros elementos litófilos de baixo potencial iônico, além de Terras Raras leves (La, $\mathrm{Ce}, \mathrm{Nd}$ ), em relação aos elementos litófilos de elevado potencial iônico (Zr, Ti, P, Nb, Y, Terras Raras Pesadas) é importante característica das rochas de afinidade shoshonítica. Ressalte-se ainda que a razão $\mathrm{K}_{2} \mathrm{O} \backslash \mathrm{Na}_{2} \mathrm{O}$ elevada, é indicativa de afinidade shoshonítica em séries saturadas, apenas para os termos básicos e intermediários; os termos mais diferenciados $\left(\mathrm{SiO}_{2}>63 \%\right.$ em peso) não apresentam enriquecimento relativo em $\mathrm{K}$.

As rochas das séries shoshoníticas ocorrem dominantemente em ambientes de arco magmático continental maturo e pós-colisionais.

\section{Geologia da Associação Shoshonítica de Lavras do}

Sul O magmatismo neoproterozóico de afinidades shoshonítica e alcalina sódica saturada em sílica, do sul do Brasil é representado por uma sucessão de rochas plutônicas e vulcânicas associadas com seqüências sedimentares que foram depositadas em bacias do tipo strike-slip, formadas nos estágios pós-colisionais do ciclo orogênico Brasiliano/Pan-africano (Sommer et al. 2006). A Associacão Shoshonitica de Lavras do Sul localiza-se na porção oeste do Escudo Sul-Rio-Grandense, extremo sul do Brasil. Esta associação de idade neoproterozóica está relacionada ao início do magmatismo alcalino do estágio pós-colisional do ciclo orogênico Brasiliano no sul do Brasil.

A ASLS tem como embasamento metagranitóides (Complexo Cambai) e xistos (Metamorfitos Arroio da Porteira) relacionados ao Ciclo Brasiliano, que são parcialmente cobertos por rochas sedimentares da Formação Maricá. Este conjunto foi sobreposto e intrudido por rochas básicas a ácidas da Associação Shoshonítica de Lavras do Sul - ASLS (Nardi \& Lima 1985). Granitos e vulcanitos ácidos e básicos, de afinidade alcalina sódica saturada em sílica (Formação Acampamento Ve1ho), e rochas sedimentares da Formação Santa Bárbara sucedem esta associação (Fig. 1).

A ASLS possui na base traquibasaltos potássicos, sucedidos por quatro ciclos efusivos shoshoníticos, além de depósitos piroclásticos correlatos (Lima 1995). Os corpos intrusivos contemporâneos aos vulcanitos da base são representados pelo Monzodiorito Arroio do Jacques, pelo Monzonito Tapera e pelos granitos do núcleo do Complexo Granítico de Lavras ambos com 


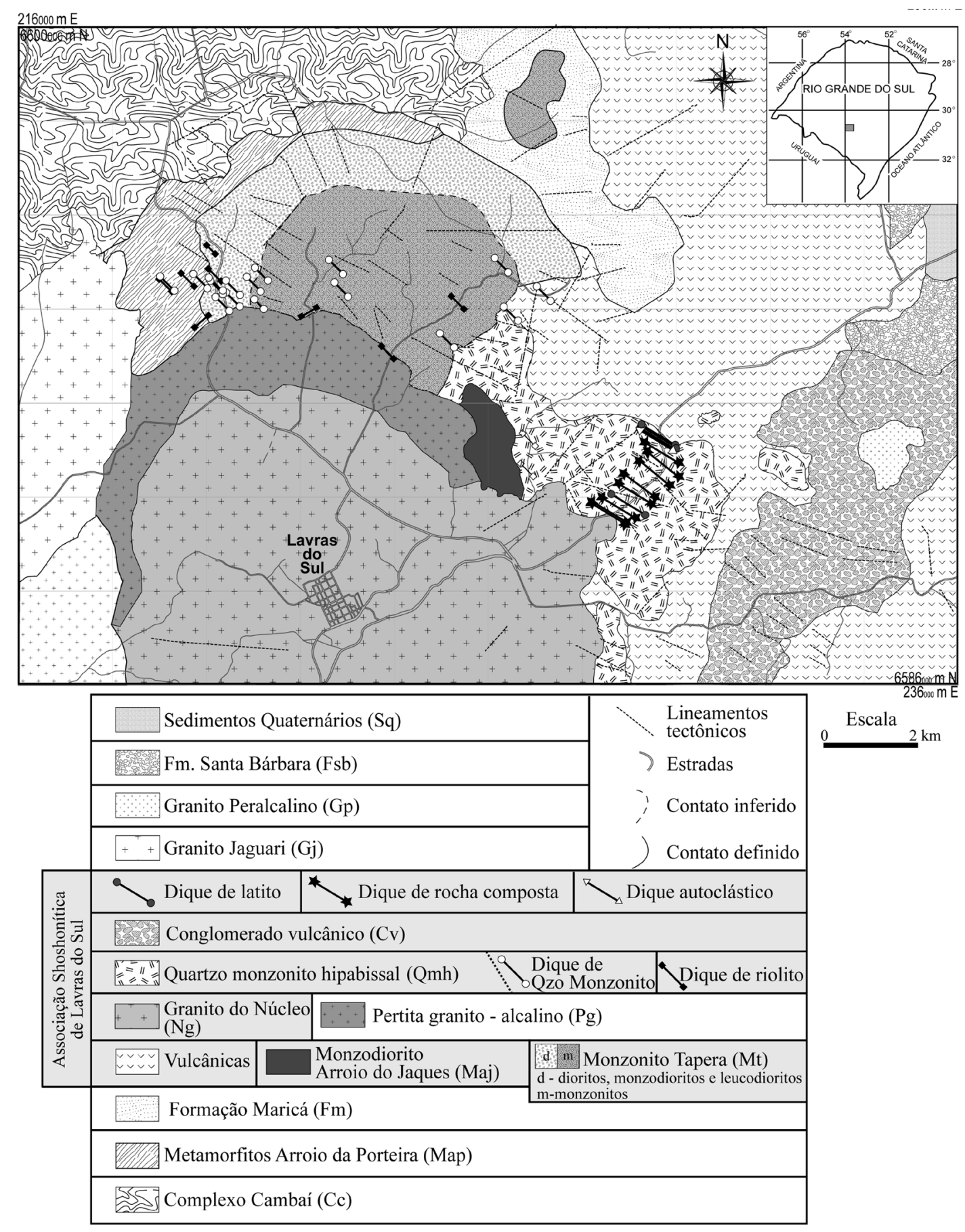

Figura 1 - Mapa geológico da porção norte de Lavras do Sul.

idades em torno de $600 \mathrm{Ma}$ (Gastal et al. 2006). O primeiro ocorre como um corpo alongado com direção NW-S e extensão de $2,5 \mathrm{~km}$ por $1 \mathrm{~km}$ de largura, sendo constituído por monzodioritos, quartzo monzodioritos e, subordinadamente, ortopiroxênio dioritos, atingindo, algumas vezes, composições monzoníticas. O Monzonito Tapera apresenta zonação normal e formato de meia-lua e é caracterizado por dioritos e leucodioritos que evoluem, em direção ao sul, para monzodioritos e monzonitos. Conforme a definição de Nardi (1984), os granitos do núcleo do Complexo Granítico de Lavras compreendem granodioritos a monzogranitos com ferro-edenita e biotita. Corpos ressurgentes hipabissais ( $\approx 587 \mathrm{Ma}$, Liz et al. 2005.) são as últimas manifestações intrusivas com afinidade shoshonítica e compreendem monzonitos e quartzo monzonitos. Estes corpos secionam o Monzonito Tapera, o Monzodiorito Arroio do Jacques, os shoshonitos e a borda nordeste do Complexo Granítico de Lavras. Temporalmente vinculados a estes corpos ocorrem os diques riolítico de espessuras decamétricas e as últimas manifestações efusivas intermediárias. Manifestações latíticas estão representadas por diques decamétricos com direção NW-SE na porção nordeste de Lavras do Sul. 
LITOQUíMICA DA ASLS A Associação Shoshonítica de Lavras do Sul (ASLS) é constituída principalmente por rochas vulcânicas básicas a intermediárias, corpos hipabissais e plutônicos dominantemente monzoníticos além de rochas monzograníticas a granodioríticas (Lima \& Nardi 1998). As características geoquímicas dos basaltos, como o caráter saturado em $\mathrm{SiO}_{2}$, baixo $\mathrm{TiO}_{2}$, conteúdo relativamente elevado de $\mathrm{Al}_{2} \mathrm{O}_{3}, \mathrm{Rb}, \mathrm{Ba}$, Sr e ETRL, razão $\mathrm{K}_{2} \mathrm{O} / \mathrm{Na}_{2} \mathrm{O}$ em torno da unidade e conteúdos moderados de HFSE determinam à afinidade shoshonítica destas rochas, bem como a sua vinculação com zonas orogênicas. Modelamentos teóricos, efetuados por Lima (1995) a partir dos conteúdos de ETR das rochas básicas, indicam que os prováveis líquidos primários foram gerados por $5 \mathrm{a}$ $10 \%$ de fusão de um manto litosférico enriquecido, cerca de 6 a 8 vezes, em ETRL e elementos de grande raio iônico. Gastal \& Lafon (2006) destacam que assinatura geoquímica dos termos básicos e intermediários da ASLS revela um enriquecimento de uma fonte mantélica por processos de subducção prévia, no entanto, estes autores sugerem a interação manto/crosta para explicar a diversidade química, especialmente dos traquiandesitos.

O modelamento teórico, efetuado por Lima (1995) indica que os vulcanitos intermediários foram gerados a partir da cristalização de basaltos shoshoníticos, com o fracionamento de olivina+clinopiroxênio. A coerência dos padrões geoquímicos e dos dados de química mineral com o modelo de cristalização fracionada não é compatível com assimilação crustal. Baixas razões iniciais de ${ }^{87} \mathrm{Sr} / \mathrm{Sr}^{86}$ (em torno de 0,704 ) e valores de $\varepsilon N d$ levemente negativo obtidos nas rochas da ASLS (Soliani Jr 1986, Remus et al.2000, Gastal \& Lafon 2006) aliado a ausência de zircões herdados sugerem que os processos de diferenciação desse magmatismo não apresentaram uma participação crustal significativa. Cálculos de balanço de massa e testes com elementos-traço indicam o fracionamento expressivo de plagioclásio, juntamente com augita +/- olivina na evolução magmática das rochas shoshoníticas, sendo este processo responsável pela geração de líquidos residuais monzoníticos e pela formação de rochas cumuláticas leucodioríticas, ocorrentes na porção nordeste do Complexo Granítico de Lavras. A cristalização fracionada de associações minerais anidras, desde os termos básicos até o início do segmento monzonítico, deve ser responsável pelo crescimento relativo de voláteis e pela estabilização precoce de anfibólio neste último. O conjunto de dados obtidos para as rochas efusivas e intrusivas é compatível com um modelo evolutivo para a ASLS e para associações shoshoníticas similares, envolvendo inicialmente a cristalização fracionada de fases ferromagnesianas, seguida de plagioclásio e finalmente por plagioclásio+ minerais máficos hidratados. Este processo é responsável por uma trajetória da diferenciação magmática paralela à porção saturada em $\mathrm{SiO}_{2}$ da linha $\mathrm{AP}$ do diagrama QAP até o campo das rochas monzoníticas, onde as composições residuais deslocam-se para o campo das rochas graníticas.

SLIDING NORMALIZATION APLICADO A ASLS A técnica de sliding normalization foi proposta por Liégeois et al. (1998), com base nos dados de litoquímica das séries de Telabit e Yenchichi, para estabelecer uma comparação geoquímica entre rochas com diferentes estágios de diferenciação pertencentes a séries magmáticas distintas. A técnica de sliding normalization minimiza os efeitos da diferenciação magmática permitindo que os conteúdos de elementos maiores e traços sejam comparados independentemente do grau de diferenciação das fusões que os originaram. Foi aplicada na ASLS tendo-se em conta que essa representa uma associação de rochas com grande variação de $\mathrm{SiO}_{2}$, representando em geral rochas co-genéticas, com evolução dominada por cristalização fracionada, formando trends compatíveis com o de líquidos co-magmáticos. As amostras selecionadas da ASLS apresentam uma variação de 51,2\% a $72,05 \%$ de $\mathrm{SiO}_{2}$, conforme consta na tabela 1 , e os dados de química destes litotipos foram utilizados na construção dos gráficos para os diferentes elementos químicos. A variação para cada elemento em relação ao índice de diferenciação é descrita por uma regressão polinomial de segunda ordem, com $\mathbf{y}=\boldsymbol{a} \mathbf{x}^{2}+\boldsymbol{b} \mathbf{x}$ $+c$, onde $\mathbf{y}=$ teor do elemento a ser determinado $\mathrm{e}$ $\mathbf{x}=$ conteúdo de $\mathrm{SiO}_{2}$ da amostra, sendo $\boldsymbol{a}, \boldsymbol{b}$ e $\boldsymbol{c}$ os coeficientes (Fig. 2; Tab. 2). Portanto, o conjunto de fórmulas permite estabelecer os teores dos elementos da ASLS para cada intervalo de $\mathrm{SiO}_{2}$.

Um diagrama multi-elementos normalizados pela ASLS (Fig. 3) foi construído para comparar a ASLS com outras associações shoshoníticas de ambiente póscolisional. A utilização deste diagrama permite obter uma gama de informações sobre as rochas, partindo da simples comparação entre os teores dos elementos químicos até a avaliação de tipos de fontes magmáticas, ambientes tectônicos e processos geradores.

A figura 3 ilustra na faixa cinza as variações dos teores da ASLS em relação ao modelo matemático construído, tornando o campo de comparação mais representativo.

Alguns aspectos devem ser considerados quando utilizamos este diagrama: (a) os dados químicos de rocha devem ser recalculados em base anidra; (b) devese utilizar rochas com teores de $\mathrm{SiO}_{2}$ entre $52 \%$ e $72 \%$; (c) e rochas com perdas ao fogo superiores a $5 \%$ ou com efeitos cumuláticos devem ser evitadas.

\section{GEOLOGIA DE UNIDADES SHOSHONÍTICAS} GERADAS EM PÓS-COLISIONAL Na comparação da química das rochas da ASLS, para estabelecer a vinculação das fontes geradoras dos magmas e os processos de cristalização fracionada, foram selecionadas cinco unidades shoshoníticas geradas em ambiente pós-colisional (Fig. 4), sendo elas o Plúton Tismana na Romênia, as rochas vulcânicas do norte do Platô do Tibet, o Domo Tormes na zona Central Ibérica (Espanha/ Portugal), as rochas intrusivas shoshoníticas do pós- 
Tabela 1 - Análise química das amostras selecionadas da ASLS.

\begin{tabular}{|c|c|c|c|c|c|c|c|c|c|c|c|c|c|c|c|c|c|c|}
\hline & -01 & -02 & LS-03 & LS-04 & LS-05 & LS-06 & LS-07 & LS-08 & LS-09 & LS-10 & LS-11 & LS-12 & LS-13 & LS-14 & LS-15 & LS-16 & LS-17 & LS-18 \\
\hline $\begin{array}{c}\mathrm{SiO}_{2} \\
\text { (\%peso) }\end{array}$ & & ,26 & 30 & 70 & 52,00 & , 00 & 52,00 & ,60 & , 90 & , 05 & 1,64 & 2,02 & 3,30 & 4,30 & 5,5 & 6,01 & 70,35 & 2,05 \\
\hline $\mathrm{Al}_{2} \mathrm{O}_{3}$ & 1 & & 11 & 50 & 25 & ,97 & 50 & 18,60 & 7,90 & 99 & 6,94 & 20 & 4,72 & 81 & 14,67 & 01 & 4,9 & 4,57 \\
\hline $\mathrm{Fe}_{2} \mathrm{O}_{3} \mathrm{t}$ & 9,44 & 7,5 & 8,77 & 9,77 & 9 , & 7,74 & 8,47 & 55 & 6,53 & 2 & 4,74 & 5,20 & 43 & 4,43 & 4,1 & 4,205 & 67 & 18 \\
\hline $\mathrm{MnO}$ & 0,12 & 0,16 & 0,15 & 0,14 & 0 , & 0.13 & 0,15 & 007 & 0,17 & 0.10 & 0,09 & 0,10 & 0,06 & 005 & 0,04 & 4 &, 04 &, 024 \\
\hline $\mathrm{MgO}$ & 12,97 & 9,17 & 13,0 & 8 & 320 & 22 & 828 & 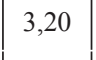 & 28 & 79 & 1 & 291 & 70 & 15 & 1,4 & 1,8 & 0,64 & 45 \\
\hline $\mathrm{CaO}$ & 7 & 7 & 7,00 & 7,20 & 700 & 6,88 & 7,36 & 50 & 7,10 & 13 & 3,88 &, 1 & 3,01 & 2,5 & 2 & 1,23 & 1,63 & 76 \\
\hline $\mathrm{Na}_{2} \mathrm{O}$ & 3,67 & 3,73 & 3,50 & 86 & 78 & 3,80 & 3,77 & 20 & 4,00 & 1,62 & 4,74 & 4,32 & 4,70 & 4,53 & 4,31 & 4,18 & 4,42 &, 03 \\
\hline $\mathrm{K}_{2} \mathrm{O}$ & 1,78 & 1,92 & 1,01 & 2,57 & 2,00 & 2,00 & 2,26 & 90 & 2,20 & 3,43 & 3,19 & 3,78 & 4,02 & 4,00 & 4,3 & 3,85 & 3,95 & 41 \\
\hline $\mathrm{TiO}_{2}$ & 0,90 & 0 & 1,00 & 0 & 1 & 0 & 0 , & 90 & 0,90 & 061 & 0,52 & 0,63 & 0,30 & 0,40 & 0,40 & 0,42 & 0,31 & 0,219 \\
\hline $\mathrm{P}_{2} \mathrm{O}_{5}$ & 0 & 0 , & 0,20 & 0 & 0 , & 0,18 & 0 , & 0,36 & 0 & 0,33 & 0 & 0 & 0,10 & 0 & 0,10 & 0,16 & 0,20 & 12 \\
\hline $\mathrm{L}$ & & & & 1,20 & & 2,74 & & 2,30 & & 0,9 & & 2,0 & 00 & 10 &, 00 & 0 & 0,86 & 18 \\
\hline Total & 100,75 & 99,27 & 100,57 & 100,95 & 99,76 & 9,57 & 100,57 & 100,20 & 99,50 & 57 & 8,62 & 9,67 & 9,34 & 9,62 & 99,82 & 99,905 & 99,97 & 9,98 \\
\hline $\begin{array}{c}\mathrm{Ba} \\
(\mathrm{ppm})\end{array}$ & 1 & 1 & & 1080 & 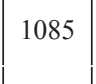 & 1050 & 1100 & 500 & $15 / 6$ & 740 & $1 / 59$ & 705 & 1593 & 1490 & 1621 & 510 & 1181 & 348 \\
\hline $\mathrm{Rb}$ & 49 & 6 & 40 & 6 & 60 & 58 & 60 & 72 & 81 & & 92 & 85 & 8 & 7 & 8 & 90 & 178 & 9 \\
\hline $\mathrm{Sr}$ & 43 & 72 & 410 & 7. & 7 & 70 & 720 & 1270 & 1166 & 1245 & 1368 & 1058 & 95 & 940 & 805 & 728 & 748 & 79 \\
\hline $\mathrm{Nb}$ & 11 & 1 & 13 & & 14 & 14 & & & 21 & 1 & 13 & 1 & 1 & & & 1. & 14 & 1 \\
\hline $\mathrm{Zr}$ & 164 & 1 & & 2 & 2 & 16 & 2 & & 2 & & 1 & 24 & 24 & 1 & 0 & 225 & 192 & 35 \\
\hline Y & n.a. & 1 & 180 & & 2500 & 16,00 & na &, 00 & 25,00 & 16,01 & 12,00 & 13,00 & 10,00 & n: & $n$ & 13,00 & 23,00 & 9,00 \\
\hline $\mathrm{Ce}$ & $\mathrm{n}$. & 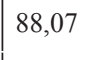 & 58,2 & 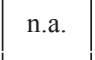 & 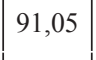 & . & n.a. & 4,02 & 94,73 & 109,30 & 103,14 & $\mathrm{n}$ & n & n.a. & 39 & a. & 73,40 & 61 \\
\hline $\mathrm{Nd}$ & n.a. & 37,32 & 29,00 & n.a. & 40,81 & n.a. & n.a. & 44,10 & 43,10 & 45,09 & 39,50 & n.a. & n.a. & n.a. & 25,09 & n.a. & 32,00 & 20,81 \\
\hline $\mathrm{Sm}$ & n.a. & 6,67 & 5,60 & n.a. & 7,20 & n.a. & n.a. & 6,85 & 10,53 & 7,75 & 6,71 & n.a. & n.a. & n.a. & 4,86 & n.a. & 5,58 & 3,32 \\
\hline $\mathrm{Yb}$ & n.a. & 1,02 & 1,13 & n.a. & 0,89 & a. & n.a. & 1,45 & 1,69 & 1,49 & 1,26 & n.a. & n.a. & n.a. & 1,42 & n.a. & 0,73 & 0,25 \\
\hline
\end{tabular}
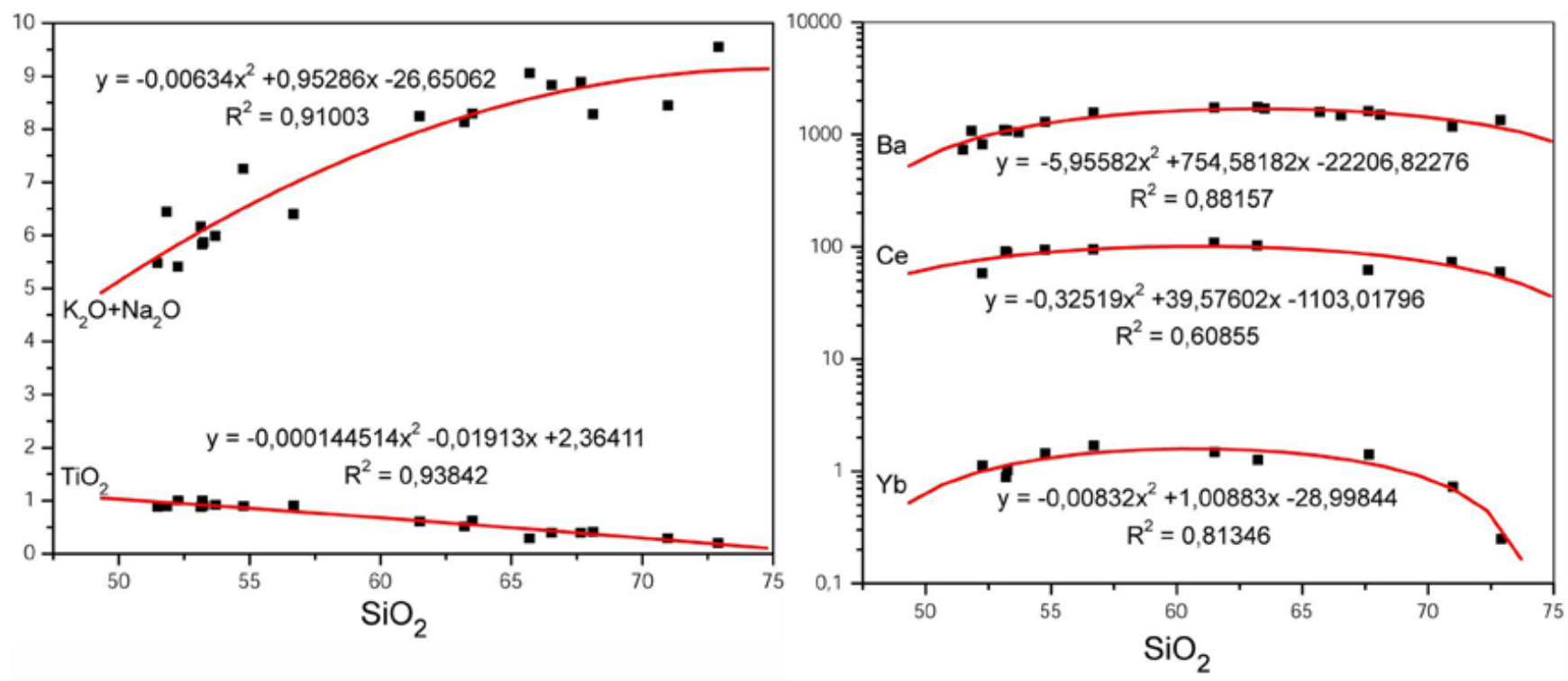

Figura 2 - Exemplos de regressão polinomial de segunda ordem utilizando alguns elementos químicos das rochas da ASLS. 
Tabela 2 - Coeficientes das curvas polinomiais de segunda ordem da ASLS $\left(y=a x^{2}+b x+c\right.$, onde $y=a o$ teor do elemento a ser determinado e $x=\mathrm{SiO}_{2}$ em base anidra).

\begin{tabular}{c|c|c|c}
\hline Elemento & $\mathrm{a}$ & $\mathrm{b}$ & $\mathrm{c}$ \\
\hline $\mathrm{K}_{2} \mathrm{O}+\mathrm{Na}_{2} \mathrm{O}$ & $-0,00634$ & 0,95286 & $-26,65062$ \\
$\mathrm{Rb}$ & 0,15184 & $-15,10309$ & 432,65577 \\
$\mathrm{Nb}$ & $-0,02084$ & 2,397 & $-52,59662$ \\
$\mathrm{~K} 2 \mathrm{O}$ & $-0,0033$ & 0,52891 & $-16,5876$ \\
$\mathrm{Ba}$ & $-5,95582$ & 754,58182 & $-22206,82276$ \\
$\mathrm{Sr}$ & $-5,14005$ & 637,62983 & $-18626,49585$ \\
$\mathrm{CaO}$ & $-0,0015$ & $-0,15258$ & 19,50014 \\
$\mathrm{Na}_{2} \mathrm{O}$ & $-0,00304$ & 0,42395 & $-10,06303$ \\
$\mathrm{TiO}_{2}$ & $-1,45 \mathrm{E}-04$ & $-0,01913$ & 2,36411 \\
$\mathrm{Fe}_{2} \mathrm{O}_{3} \mathrm{t}$ & $-0,00141$ & $-0,15701$ & 20,95745 \\
$\mathrm{Zr}$ & $-0,56629$ & 68,74705 & $-1847,07795$ \\
$\mathrm{Ce}$ & $-0,32519$ & 39,57602 & $-1103,01796$ \\
$\mathrm{Nd}$ & $-0,12182$ & 14,50044 & $-389,01648$ \\
$\mathrm{Sm}$ & $-0,02585$ & 3,07463 & $-83,48242$ \\
$\mathrm{Y}$ & 0,01931 & $-2,73624$ & 110,57016 \\
$\mathrm{Yb}$ & $-0,00832$ & 1,00883 & $-28,99844$ \\
\hline
\end{tabular}

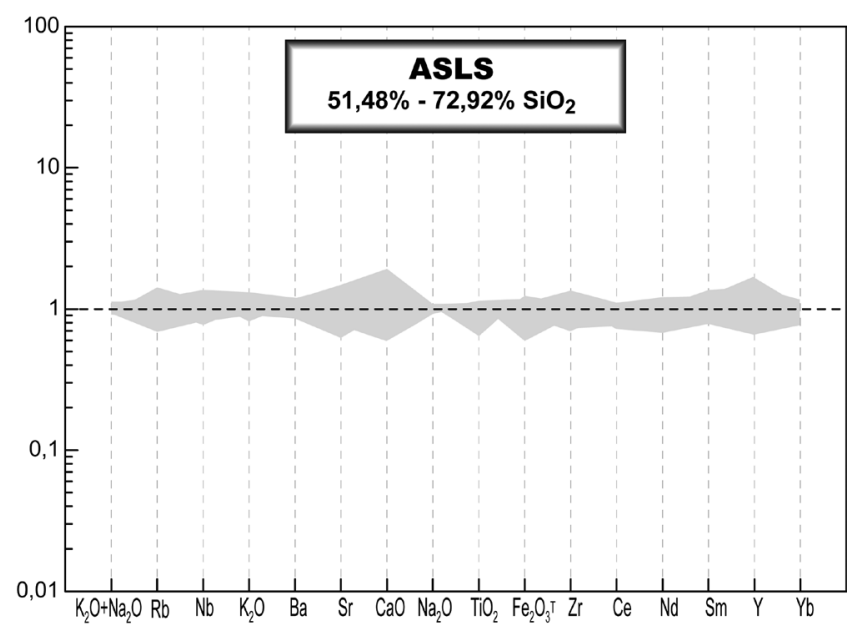

Figura 3 - Diagrama multi-elementos de normalização da Associação Shoshonitica de Lavras do Sul (ASLS).

colisional Svecofenniano no sul da Finlândia e República da Carélia e o Quartzo-monzonito Baranadag da Turquia. A escolha dessas unidades deve-se a representatividade de cada associação de rochas com afinidade shoshonítica, de acordo com os critérios adotados neste artigo: foram geradas em ambiente pós-colisional e possuem análises químicas com os elementos químicos necessários para a aplicação da técnica. Os dados utili- zados constam na tabela 3 .

Plúton Tismana Representa um corpo plutônico formado por um conjunto de rochas de afinidade shoshonítica que faz parte do embasamento Pré-cambriano das nappes Alpino-Danubianas da Romênia. Este corpo, com idade de $567 \pm 3 \mathrm{Ma}$, foi gerado no pós-colisional Pan-Africano, sem influência de zonas transcorrentes, e representa uma série shoshonítica contínua de 50\% até $75 \%$ de $\mathrm{SiO}_{2}$ com monzogabros, monzonitos, quartzomonzonitos, quartzo-monzodioritos, quartzo-sienitos, monzogranitos e granodioritos.

Duchesne et al. (1998), com base nos dados isotópicos de $\mathrm{Sr}_{i}<0,7049$ e um $\varepsilon \mathrm{Nd}>+0,5$, sugerem que as rochas do Plúton Tismana foram formadas principalmente por cristalização fracionada com pouca contaminação crustal e sugerem duas possíveis fontes para as rochas: fusão de manto litosférico ou fusão de crosta inferior máfica, sendo que, em ambos os casos precisam ser enriquecidas em $\mathrm{K}_{2} \mathrm{O}$ e elementos associados. Este processo de enriquecimento deve estar relacionado aos processos de subducção durante a Orogenia Panafricana (Duchesne et al. 1998).

Rochas Vulcânicas do Norte do Platô do Tibet (Kunlun) O Platô do Tibete, o Himalaia e as Cordilheiras de Karakoram são produtos da colisão da Índia com a margem meridional da Eurásia durante os últimos $50 \mathrm{Ma}$ (Miller et al.1999). Molnar et al. (1993) sugeriram que o início do pós-colisional no norte do Platô do Tibet ocorreu em torno de 8 Ma e é representado pelo magmatismo basáltico potássico, sendo interpretado como o resultado da transferência rápida de calor para a porção média da litosfera causada pela remoção da base da litosfera.

As rochas efusivas de afinidade shoshonítica que ocorrem na localidade de Kulun, porção norte do Platô do Tibet, possuem idade em torno de $5 \mathrm{Ma}$ e ocupam no diagrama TAS o campo dos latitos (Williams et al. 2004).

Dados isotópicos iniciais de $\varepsilon \mathrm{Nd}(-5,0$ a $-5,8)$ e ${ }^{87} \mathrm{Sr} /{ }^{86} \mathrm{Sr}(0,707892$ a 0,708179$)$ aliados a assinatura dos elementos maiores sugerem uma derivação de manto litosférico subcontinental enriquecido por metassomatismo relacionado a subducção (Williams et al. 2004). Estes autores não apresentam dados que sugiram relações direta destes litotipos com zonas de cisalhamento.

Um modelamento com base em elementos-traço efetuado por Williams et al. (2004) sugeriu que as rochas vulcânicas do norte do Platô do Tibete foram formadas a partir de $3 \%$ a $4 \%$ de fusão parcial de um flogopita peridotito.

Domo Tormes Localiza-se no Cinturão Ibérico Variscan na zona Central Ibérica que abrange a Espanha e Portugal. Este domo é formado por dois cinturões: Ifanes-Sayago e Vitigudino (López-Plaza et al. 1999) que compreendem os Plútons Pereruela e Vitigudino, respectivamente. Esses plútons são relacionados a zonas de cisalhamento de baixo ângulo, sendo constituídos por uma associação de rochas com afinidade shoshonítica com monzodioritos, monzonitos, quartzo monzonitos e mon- 


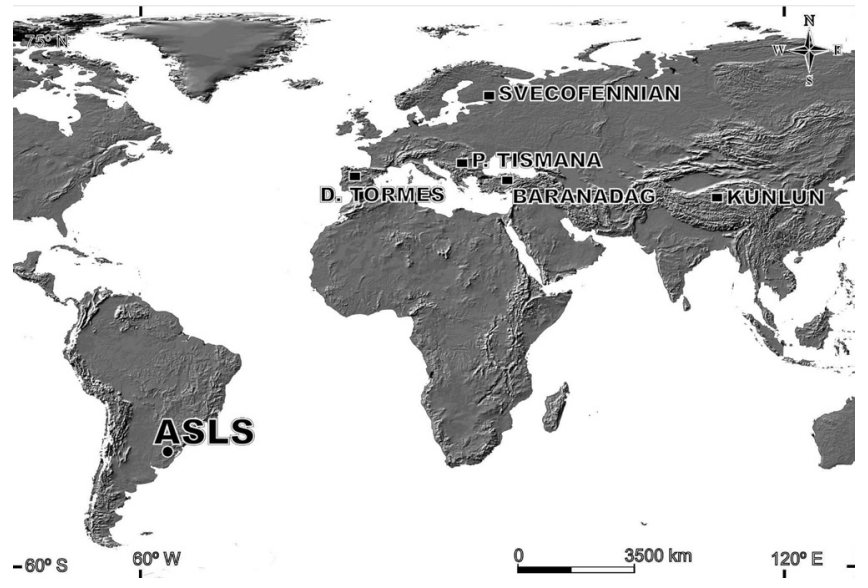

Figura 4 - Mapa de localização das rochas shoshoniticas geradas em ambiente pós-colisional utilizadas neste estudo.

zogranitos (López-Plaza et al. 1999). A idade de $320 \mathrm{Ma}$ obtida em um biotita granito do Cinturão Ifanes-Sayago é a única referência geocronológica do Domo Tormes, sendo esta a idade mínima para os plútons Pereruela e Vitigu- dino, assumindo que relações de campo demonstram que são precedentes (López-Moro \& López-Plaza 2003).

Dados isotópicos de $\varepsilon N d(-2,9$ a $-5,5),{ }^{87} \mathrm{Sr}^{86}{ }^{86} \mathrm{Sr}_{\mathrm{i}}$ $(0,707079$ a 0,707849$)$ e $\delta^{18} \mathrm{O}(+8,4 \%$ a $+9,0 \%)$ para o Púton Pereruela e $\varepsilon N d(-3,5$ a $-6,5),{ }^{87} \mathrm{Sr} /{ }^{86} \mathrm{Sr}(0,707035$ a 0,711751$)$ e $\delta^{18} \mathrm{O}(+9,8 \mathrm{a}+11,1)$ para o Plúton Vitigudino aliado a um modelamento com assimilação combinada à cristalização fracionada (AFC) usando elementos maiores e traço sugerem que diferentes contaminantes crustais participaram na geração dos dois plútons: um gnaisse granulítico no Plúton Pereruela e um metapelítico no Plúton Vitigudino (López-Moro e López-Plaza 2003). Conforme estes autores, os Plútons Pereruela e Vitigudino foram formados a partir de um evento de slab break-off tardi-orogênico com subsequente extensão pós-colisional, que gerou a fusão parcial de um protólito híbrido, correspondendo a uma mistura de peridotito, anfibolito e metapelito próximo ao limite crosta/manto.

Magmatismo pós-colisional Svecofenniano É marcado por rochas intrusivas de afinidade shoshonítica que ocorrem em um cinturão com extensão em torno de $600 \mathrm{~km}$, com trend $\mathrm{E}-\mathrm{W}$, abrangendo desde as ilhas

Tabela 3 - Análise química das amostras das unidades: Domo Tormes (DT), Plúton Tismana (PT), Kunlun (KN), Baranadag (BG) e Svecofennian (SF).

\begin{tabular}{|c|c|c|c|c|c|c|c|c|c|c|c|c|c|c|c|c|c|}
\hline Amostra & PER-B & POR-15 & PER-A & POR-14 & $\begin{array}{c}\text { POR- } \\
14 \mathrm{~B}\end{array}$ & $\begin{array}{c}\text { POR- } \\
106\end{array}$ & $\begin{array}{c}\text { POR- } \\
109\end{array}$ & SV9 & SV10 & SV15 & SV16 & SV18 & SV20 & T-504 & T-1029 & T-R17 & $\mathrm{T}-51$ \\
\hline Unidade & D. T. & D. T. & D. T. & D. T. & D. T. & D. T. & D. T. & SF & $\mathrm{SF}$ & $\mathrm{SF}$ & $\mathrm{SF}$ & $\mathrm{SF}$ & $\mathrm{SF}$ & P.T. & P.T. & P.T. & P.T. \\
\hline Referências & 1 & 1 & 1 & 1 & 1 & 1 & 1 & 2 & 2 & 2 & 2 & 2 & 2 & 3 & 3 & 3 & 3 \\
\hline $\mathrm{SiO}_{2}(\%$ peso $)$ & 54,22 & 57,95 & 58,16 & 63,85 & 70,68 & 52,78 & 66,75 & 51,57 & 65,06 & 51,13 & 67,08 & 56,27 & 71,45 & 51,3 & 51,49 & 52,07 & 57,94 \\
\hline $\mathrm{Al}_{2} \mathrm{O}_{3}$ & 18,18 & 17,51 & 16,15 & 16,94 & $|15,97|$ & 17,05 & 17,09 & 15,4 & 14,82 & 14,75 & 15,3 & 14,7 & 13,75 & 17 & $|17,94|$ & 16,39 & 16,11 \\
\hline $\mathrm{Fe}_{2} \mathrm{O}_{3}$ & 4,91 & 5,17 & 4,88 & 3,57 & 0,04 & 0,68 & 0,19 & 9,65 & 4,98 & 10,2 & 3,15 & 8,33 & 2,69 & 8,62 & 9,38 & 11,41 & 8,07 \\
\hline $\mathrm{MnO}$ & 0,06 & 0,06 & 0,05 & 0,03 & 0,02 & 0,11 & 0,02 & 0,09 & 0,04 & 0,14 & 0,05 & 0,13 & 0,03 & 0,14 & 0,16 & 0,19 & 0,11 \\
\hline $\mathrm{MgO}$ & 4,58 & 3,45 & 3,77 & 1,86 & 0,57 & 5,46 & 0,78 & 3,04 & 1,27 & 4,43 & 1,16 & 4,21 & 0,8 & 5,69 & 4,61 & 3,34 & 2,85 \\
\hline $\mathrm{CaO}$ & 5,45 & 4,25 & 4,33 & 2,46 & 1,33 & 6,54 & 1,35 & 6,15 & 2,6 & 6,74 & 2,15 & 5,57 & 1,18 & 6,6 & 5,73 & 5,43 & 4,19 \\
\hline $\mathrm{Na}_{2} \mathrm{O}$ & 3,39 & 3,26 & 3,64 & 3,17 & 3,12 & 2,8 & 3,15 & 3,56 & 3,22 & 3,09 & 3,42 & 3,09 & 2,48 & 2,11 & 3,02 & 2,43 & 2,58 \\
\hline $\mathrm{K}_{2} \mathrm{O}$ & 5,22 & 5,5 & 5,29 & 6,06 & 6,48 & 5,2 & 7,57 & 2,87 & 4,24 & 2,98 & 5,68 & 3,39 & 6,23 & 2,88 & 3,52 & 4,24 & 4,56 \\
\hline $\mathrm{TiO}_{2}$ & 0,49 & 0,87 & 0,4 & 0,6 & 0,18 & 1,18 & 0,34 & 2,62 & 1,1 & 2,16 & 0,72 & 1,66 & 0,38 & 1,7 & 1,25 & 1,8 & 1,41 \\
\hline $\mathrm{P}_{2} \mathrm{O}_{5}$ & 0,88 & 0,9 & 0,98 & 0,52 & 0,21 & 0,62 & 0,34 & 1,33 & 0,5 & 1,6 & 0,21 & 1,09 & 0,1 & 0,54 & 0,6 & 1,03 & 0,49 \\
\hline LOI & 1,09 & 0,1 & 1,79 & 0,5 & 0,55 & 1,76 & 0,82 & 0,77 & 0,71 & 0,88 & 0,65 & n.a. & n.a. & 2,73 & 1,98 & 1,46 & 1,25 \\
\hline Total & 98,47 & 98,96 & 99,45 & 99,55 & $|100,15|$ & 99,03 & 99,67 & 97,05 & 98,54 & 98,1 & 99,57 & 98,44 & 99,09 & 99,31 & $|99,68|$ & 99,79 & 99,56 \\
\hline $\mathrm{Ba}(\mathrm{ppm})$ & 2500 & 2776 & 2100 & 1623 & 1957 & 2905 & 1111 & 3233 & 2222 & 4010 & 4423 & 2528 & 1853 & 1182 & 1478 & 2014 & 1522 \\
\hline $\mathrm{Rb}$ & 150 & 174,8 & 160 & 232,7 & 180 & 207 & 254 & 99 & 161 & 50 & 103 & 82 & 160 & 167 & 143 & 151 & 153 \\
\hline $\mathrm{Sr}$ & n.a. & 1596 & n.a. & 697 & 670 & 1116 & 366 & 2179 & 893 & 2152 & 1232 & 1307 & 554 & 835 & 1281 & 744 & 545 \\
\hline $\mathrm{Nb}$ & 18 & 28,1 & 22 & 12,4 & 4,6 & 10 & 6,2 & 53 & 33 & 30 & 32 & 29 & 36 & 52 & 53 & 92 & 57 \\
\hline $\mathrm{Zr}$ & n.a. & 380 & n.a. & 282 & 112 & 241 & 132 & 700 & 512 & 397 & 536 & 403 & 276 & 305 & 265 & 519 & 517 \\
\hline Y & n.a. & 27,5 & n.a. & 16,1 & 5,1 & 23,5 & 9,5 & 34 & 15 & 39 & 42 & 35 & 28 & 36 & 25 & 46 & 43 \\
\hline $\mathrm{Ce}$ & 246 & 369,5 & 300 & 119,4 & $49,06 \mid$ & 328 & 106,8 & 498 & 275 & 342 & 335 & 281 & 253 & 116 & 150 & 266 & 162 \\
\hline $\mathrm{Nd}$ & 104 & 142,1 & 121 & 47,02 & $|17,59|$ & 133,4 & 38,97 & 192 & 89 & 133 & 125 & 108 & 80 & 49 & 58 & 119 & 75 \\
\hline $\mathrm{Sm}$ & 15 & 18,52 & 16 & 8,24 & 2,75 & 18,57 & 6,79 & 26,6 & 11,6 & 18,9 & 16,8 & 15,9 & 10,3 & 8,4 & 8,4 & 17,9 & 14 \\
\hline $\mathrm{Yb}$ & 2 & 2,21 & 2 & 1,32 & 0,51 & 1,81 & 0,69 & 1,57 & 0,74 & 2,84 & 3,55 & n.a. & 2,48 & 2,41 & 2,23 & 3,88 & 3,53 \\
\hline
\end{tabular}

a - elemento não analisado;

Referências: 1- López-Moro e López-Plaza (2003); 2 - Eklund et al. (1998); 3 - Duchesne et al. (1998); 4 - Köksal et al.(2004); 5 - Ilbeyli et al.(2004); 6 - Williams et al. (2004). 
Continuação da Tabela 3.

\begin{tabular}{|c|c|c|c|c|c|c|c|c|c|c|c|c|c|c|c|c|c|}
\hline Amostra & 926 & -R27 & $\mathrm{T}-1316$ & $\mathrm{~T}-1264$ & T-1313 & $\mathrm{T}-1265$ & $\mathrm{~T}-53$ & T-927 & T-1256 & T-1266 & BR-a & BR-b & BR-c & Br-d & BR-e & BR-f & N26 \\
\hline Unidade & P.T. & P.T. & P.T. & P.T. & P.T. & P.T. & P.T. & P.T. & P.T. & P.T. & BG & BG & BG & BG & BG & BG & BG \\
\hline Referênci & 3 & 3 & 3 & 3 & 3 & 3 & 3 & 3 & 3 & 3 & 4 & 4 & 4 & 4 & 4 & 4 & 5 \\
\hline $\mathrm{O}_{2}(\%$ peso $)$ & 53,19 & 54,91 & 58,79 & 59,64 & 61,81 & 63,77 & 69,64 & 67,14 & 68,16 & 70,01 & 59,50 & 59,60 & 59,90 & 59,03 & 58,04 & 59,67 & 58,44 \\
\hline $\mathrm{Al}_{2} \mathrm{O}_{3}$ & 15,24 & 16,21 & 15,37 & 15,48 & 15,41 & 14,22 & 14,04 & 15,13 & 14,57 & 14,38 & 17 & 17,2 & 17,4 & 17,3 & 17,2 & 17,3 & 17,62 \\
\hline $\mathrm{Fe}_{2} \mathrm{O}_{3}$ & 11,43 & 9,86 & 8,39 & 7,87 & 6,77 & 6,02 & 3,05 & 3,78 & 4,06 & 3,56 & 5,07 & 5,18 & 4,8 & 5,01 & 5,45 & 4,98 & 5,42 \\
\hline $\mathrm{MnO}$ & 0,16 & 0,16 & 0,13 & 0,11 & 0,08 & 0,08 & 0,04 & 0,07 & 0,04 & 0,03 & 0,1 & 0,1 & 0,1 & 0,11 & 0,11 & 0,1 & 0,13 \\
\hline $\mathrm{MgO}$ & 2,76 & 2,71 & .57 & 2 , & 1,87 & 1,61 & 1,11 & 1,08 & 1,07 & 0,48 & 1,63 & 1,72 & 1,57 & 1,58 & $\mid 1,82$ & 1,54 & 1,85 \\
\hline $\mathrm{CaO}$ & 5 , & 4,52 & 4,22 & 3,77 & 3 & 04 & 1 & 193 & 15 & 1,52 & 4,76 & 5,03 & 4,87 & 7 & 5,59 & 4,87 & 5,95 \\
\hline $\mathrm{Na}_{2} \mathrm{O}$ & 2,6 & 2,91 & 2,73 & 2,73 & 2,42 & 2,46 & 2,87 & 2,57 & 2,41 & 2,64 & 3,5 & 3,63 & 3,62 & 3,47 & 3,46 & 3,49 & 3,73 \\
\hline $\mathrm{K}_{2} \mathrm{O}$ & 3, & 4 & 3,46 & 4,42 & 474 & 4,71 & 5,22 & 6,63 & 5,42 & 5,46 & 6,02 & 5,7 & 6 & 6,59 & 5,84 & 6,35 & 5,52 \\
\hline $\mathrm{TiO}_{2}$ & 1,94 & 1,56 & 56 & 14 & 1,17 & 1,11 & 0,65 & 64 & 0,7 & 0,56 & 0,53 & 0,55 & 0,51 & 0,52 & 0,56 & 0,53 & 0,59 \\
\hline $\mathrm{P}_{2} \mathrm{O}_{5}$ & 1 & 0,79 & 0,48 & 0,48 & 0,41 & 0,36 & 0,2 & 0,23 & 0,35 & 0,2 & 0,23 & 0,26 & 0,25 & 0,29 & 0,28 & 0,24 & 0,24 \\
\hline LOI & 1,67 & 1 & 1,73 & 1,62 & 1,48 & 1,72 & 1,25 & 0,98 & 0,96 & 1,19 & 1,2 & 0,6 & 0,6 & 0,6 & 0,8 & 0,8 & 0,58 \\
\hline Total & 99,15 & 99,53 & 99,43 & 99,63 & 99,63 & & 99,63 & $\mid 100,18$ & 99,9 & $\mid 100,03$ & 99,7 & 99,7 & 99,7 & 99,8 & 99,7 & 99,9 & 99,48 \\
\hline $\mathrm{Ba}(\mathrm{ppm})$ & 2074 & 1864 & 1187 & 1676 & 1496 & 1539 & 1522 & 1586 & 1462 & 773 & 1080 & 1050 & 1090 & 1130 & 1290 & 1110 & 933 \\
\hline $\mathrm{Rb}$ & 12 & & & & & & & & 15 & 229 & 24 & 23 & 23 & 210 & 205 & 233 & 193 \\
\hline $\mathrm{Sr}$ & 62 & 561 & 595 & 57 & 447 & 51 & 510 & 47 & 391 & 231 & 970 & 964 & 952 & 964 & 1070 & $\mid 1010$ & 911 \\
\hline $\mathrm{Nb}$ & 10 & 7 & 5 & 5 & 62 & 4 & 2 & 39 & 3 & 43 & 21,00 & 23,00 & 22,00 & 19,00 & $|23,00|$ & 24,00 & 26,00 \\
\hline $\mathrm{Zr}$ & 472 & 442 & 336 & 545 & 554 & 560 & 376 & 364 & 402 & 336 & 251 & 254 & 219 & 216 & 256 & 275 & 277 \\
\hline Y & 60 & 12 & م & 27 & & 2 & 1 & 02 & 10 & 1 & 20 & 28 & 20 & 2 & 29 & 29 & 36 \\
\hline $\mathrm{Ce}$ & 198 & 227 & 129 & 154 & 178 & 153 & 321 & 109 & 115 & 158 & 129 & 134 & 134 & 118 & 157 & 151 & 157,48 \\
\hline $\mathrm{Nd}$ & 97 & & 54 & & & 61 & & & 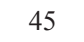 & 62 & & 55 & & 49 & 61 & 57 & $\mid 60,12$ \\
\hline $\mathrm{Sn}$ & 16 & & & 11,7 & & 8 & & 7 & 6,6 & 9 & 9, & 9 & 9, & 8,2 & 10,6 & 9,5 & 9,9 \\
\hline $\mathrm{Yb}$ & 4,96 & 89 & 2,82 & 2 & 3,57 & 2,35 & 1,23 & 2,15 & 1,67 & $1,5 \mathrm{~s}$ & 2,2 & 2,3 & 2,4 & 2,1 & 2,5 & 2,5 & 2,64 \\
\hline
\end{tabular}

\begin{tabular}{|c|c|c|c|c|c|c|c|c|c|c|c|c|c|c|c|}
\hline Amostra & N304 & N19 & N18 & N303 & N15 & N16 & $\begin{array}{c}\text { K9024- } \\
\text { NC }\end{array}$ & $\begin{array}{c}\text { K9026- } \\
\text { NC }\end{array}$ & $\begin{array}{c}\text { K9027- } \\
\text { NC }\end{array}$ & $\begin{array}{c}\text { K9028- } \\
\text { NC }\end{array}$ & $\begin{array}{c}\text { K9029- } \\
\text { NC }\end{array}$ & $\begin{array}{c}\text { K9031- } \\
\text { NC }\end{array}$ & $\begin{array}{c}\text { K9032- } \\
\text { NC }\end{array}$ & $\begin{array}{c}\text { K9038- } \\
\text { NC }\end{array}$ & $\begin{array}{c}\text { K9039- } \\
\text { NC }\end{array}$ \\
\hline Unidade & BG & BG & $\mathrm{BG}$ & BG & BG & BG & $\mathrm{KN}$ & $\mathrm{KN}$ & $\mathrm{KN}$ & $\mathrm{KN}$ & $\mathrm{KN}$ & $\mathrm{KN}$ & $\mathrm{KN}$ & $\mathrm{KN}$ & $\mathrm{KN}$ \\
\hline Referênias & 5 & 5 & 5 & 5 & 5 & 5 & 6 & 6 & 6 & 6 & 6 & 6 & 6 & 6 & 6 \\
\hline $\mathrm{iO}_{2}(\%$ peso $)$ & 58,52 & 60,93 & 61,33 & 61,85 & 62,07 & 62,62 & 57,70 & 58,00 & 57,90 & 56,90 & 57,40 & 57,30 & 58,30 & 57,20 & 58,10 \\
\hline $\mathrm{Al}_{2} \mathrm{O}_{3}$ & 17,47 & 17,39 & 17,35 & 18,26 & 17,43 & 17,77 & 15,70 & 16,00 & 16,10 & 15,60 & 15,90 & 15,60 & 15,90 & 16,20 & 16,70 \\
\hline $\mathrm{Fe}_{2} \mathrm{O}_{3}$ & 5,16 & 4,81 & 4,59 & 3,49 & 3,97 & 4,25 & 7,20 & 6,80 & 6,90 & 6,60 & 6,80 & 7,00 & 7,30 & 6,10 & 7,70 \\
\hline $\mathrm{MnO}$ & 0,12 & 0,12 & 0,11 & 0,09 & 0,1 & 0,1 & 0,10 & 0,10 & 0,10 & 0,10 & 0,10 & 0,10 & 0,10 & 0,20 & 0,00 \\
\hline $\mathrm{MgO}$ & 1,78 & 1,74 & 1,67 & 1,13 & 1,2 & 1,34 & 3,30 & 2,80 & 2,90 & 2,90 & 2,80 & 3,40 & 2,90 & 2,60 & 1,30 \\
\hline $\mathrm{CaO}$ & 5,56 & 4,16 & 4,24 & 3,58 & 3,9 & 3,94 & 5,80 & 5,50 & 5,40 & 8,00 & 6,40 & 6,50 & 5,10 & 7,60 & 5,90 \\
\hline $\mathrm{Na}_{2} \mathrm{O}$ & 3,78 & 3,81 & 3,88 & 3,93 & 3,83 & 3,79 & 3,80 & 4,00 & 4,00 & 3,80 & 4,0 & 3,70 & 3,90 & 80 & 3,90 \\
\hline $\mathrm{K}_{2} \mathrm{O}$ & 5,81 & 5,37 & 5,33 & 6,68 & 5,66 & 5 , & & & & 3,80 & 4,10 & 3 & 4,10 & 3,80 & 3,80 \\
\hline $\mathrm{TiO}_{2}$ & 0,56 & 0,51 & 0,51 & 0,39 & 0,4 & 0 , & 1 , & 1,70 & 1,70 & 1,60 & 1, & 1 , & 50 & 1,60 & 1,80 \\
\hline $\mathrm{P}_{2} \mathrm{O}_{5}$ & 0,25 & 0,22 & 0,21 & 0,14 & 0,1 & 0,19 & 0 & 0,80 & 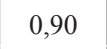 & 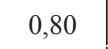 & 0 , & 0 , & 0,80 & 0,90 & 0 \\
\hline LOI & 0,78 & 0,38 & 0,65 & $0, \sigma$ & 0,77 & 0,41 & 1,00 & & & 3,80 & 1, & 2,00 & 0,90 & סט, & 2,00 \\
\hline Total & 99 & 99,06 & 99,22 & |99,54 & 98,75 & 99,83 & 101,80 & 100,80 & 100,80 & 103,90 & 101,90 & \begin{tabular}{|l|l}
101,90 \\
\end{tabular} & 100,90 & 103,30 & 102,40 \\
\hline $\mathrm{Ba}(\mathrm{ppm})$ & 959 & 965 & 940 & 1097 & 899 & 904 & 1605,90 & 1672,90 & 1609,60 & 1609,70 & 1701,00 & 1731,80 & 1815,90 & 1426,70 & 1576,60 \\
\hline $\mathrm{Rb}$ & 222 & 214 & 215 & 235 & 204 & 204 & 109,80 & 116,40 & 111,30 & 106,70 & 126,20 & 118,40 & 118,60 & 93,60 & 92,60 \\
\hline $\mathrm{Sr}$ & 920 & 583 & 576 & 566 & 579 & 579 & 981,90 & 898,70 & 969,00 & 967,90 & 1077,90 & 1001,40 & 1057,30 & 1073,70 & 1003,30 \\
\hline $\mathrm{Nb}$ & 24,00 & 20,00 & 20,00 & 20,00 & 18,00 & 20,00 & 40,90 & 44,90 & 42,60 & 40,60 & 46,60 & 43,70 & 43,90 & 39,20 & 43,00 \\
\hline $\mathrm{Zr}$ & 291 & 257 & 249 & 233 & 219 & 226 & 412,20 & 432,40 & 426,10 & 400,70 & 461,60 & 440,50 & 443,80 & 323,70 & 341,10 \\
\hline $\mathrm{Y}$ & 33 & 34 & 33 & 37 & 33 & 31 & 24,10 & 24,00 & 23,40 & 23,00 & 24,60 & 24,80 & 25,60 & 23,40 & 25,70 \\
\hline $\mathrm{Ce}$ & 135,35 & $|136,62|$ & $\mid 120,81$ & $|120,58|$ & 111,19 & 123,5 & 214,30 & 231,30 & 224,50 & 204,80 & 225,10 & $\mid 229,10$ & 235,20 & 163,70 & 177,80 \\
\hline $\mathrm{Nd}$ & 57,65 & 52,37 & 47,59 & 48,46 & 44,12 & 47,94 & 84,40 & 90,40 & 87,60 & 81,00 & 88,30 & 90,70 & 89,90 & 70,50 & 76,30 \\
\hline $\mathrm{Sm}$ & 9,53 & 8,69 & 7,75 & 8,03 & 6,91 & 8,02 & 11,80 & 12,80 & 12,20 & 11,30 & 12,40 & 12,80 & 13,20 & 10,40 & 11,40 \\
\hline $\mathrm{Yb}$ & 2,71 & 2,43 & 2,29 & 2,49 & 2,36 & 2,41 & 1,70 & 1,70 & 1,70 & 1,60 & 1,70 & 1,80 & 1,80 & 1,70 & 1,90 \\
\hline
\end{tabular}


Aland (Finlândia) até a República da Carélia (Rússia) no norte da Europa. Estas rochas com idades entre 1857 Ma e 1770 Ma posicionaram-se 30 a 50 Ma após o pico do metamorfismo representado pelo último estágio compressional da orogenia Svecofenniana (Eklund et al. 1998). As rochas intrusivas formam uma série shoshonítica com $\mathrm{SiO}_{2}$ no intervalo entre $32 \%$ e $78 \%$. Dados preliminares de isótopos $\varepsilon \mathrm{Nd} \approx+0,5$ nas intrusões do Åva e ${ }^{87} \mathrm{Sr} /{ }^{86} \mathrm{Sr}_{i} 0,7031$ a 0,7047 nas intrusões do Elisenvaara aliados a dados de geoquímica sugerem que as rochas intrusivas shoshoníticas do pós-colisional Svecofenniano foram geradas por fusão de manto litosférico afetado por metassomatismo com evolução por cristalização fracionada sem significante contaminação crustal (Eklund et al. 1998).

Quartzo-monzonito Baranadag Ocorre na porção oeste do Complexo Cristalino Central Anatolian, ao norte da Província de Kirsehir na Turquia. Esta rocha de afinidade shoshonítica (segundo a definição adotada neste artigo) possui idade de $74 \pm 2,8 \mathrm{Ma}$ e representa uma das últimas manifestações magmáticas do final do pós-colisional da Orogenia Alpina na Turquia (Köksal et al.2004).

Ilbeyli et al. (2004) sugere com base em dados isotópicos iniciais de ${ }^{87} \mathrm{Sr} /{ }^{86} \mathrm{Sr}(0,70804)$ e ${ }^{143} \mathrm{Nd} /{ }^{144} \mathrm{Nd}$ $(0,51227)$ que o magma que gerou o Quartzo-monzonito Baranadag se formou por fusão de manto litosférico subcontinental enriquecido com subsequente contaminação crustal combinado com cristalização fracionada.

COMPARAÇÃO DA ASLS COM OUTRAS UNIDADES DO MUNDO O campo definido para a ASLS utilizando sliding normalization representa uma associação de rochas shoshoníticas típica de um ambiente póscolisional, sem influência das principais zonas de deformação transcorrentes do Escudo Sul-Rio-Grandense. Os dados disponíveis para ASLS sugerem que os padrões geoquímicos estão relacionados a fontes mantélicas modificadas pelo metassomatismo relacionado a uma subducção anterior sem a participação de fontes crustais. Esta condição permite comparar os padrões geoquímicos de outras associações de rochas normalizadas pela Associação Shoshonítica de Lavras do Sul. Este procedimento permite avaliar tipos de fontes magmáticas, ambientes tectônicos e processos geradores. Esta normalização permitiu identificar as seguintes feições:

Domo Tormes Os padrões geoquímicos (Fig. 5a) indicam um enriquecimento de $\mathrm{Rb}$ e $\mathrm{K}_{2} \mathrm{O}$, com razões $\mathrm{K}_{2} \mathrm{O}$ / $\mathrm{Na}_{2} \mathrm{O}$ mais elevadas e empobrecimento de $\mathrm{Nb}$ e $\mathrm{Na}_{2} \mathrm{O}$ e uma maior variabilidade nos teores de $\mathrm{Sr}, \mathrm{Fe}_{2} \mathrm{O}_{3}{ }^{\mathrm{T}}, \mathrm{TiO}_{2}$ e ETRL. Estas feições podem ser atribuídas a contaminação crustal dos magmas aliado ao fracionamento de fases acessórias, tais como apatita e alanita (AFC). Esta contaminação é admitida por López-Moro \& LópezPlaza (2003) que sugerem a assimilação de um componente metapelítico e de gnaisses granulíticos na geração do Domo Tormes. Dados isotópicos obtidos por esses autores na amostra POR-109 (Plúton Vitigudino) indicam valores de $\mathrm{Sr} / \mathrm{Sr}_{(\mathrm{i})} 0,711751, \varepsilon \mathrm{Nd}-6,5$ e $\delta^{18} \mathrm{O}+9,8$ a
$+11,1$ que corroboram esta hipótese. O Domo de caráter sin-tectônica posicionou-se em zonas de cisalhamento de baixo ângulo, ambiente tectônico este que pode ter facilitado processos de contaminação crustal. Bitencourt \& Nardi (2000) observaram que os granitóides posicionados sincronicamente em cinturões de cisalhamento pós-colisionais no sul do Brasil mostram-se mais contaminados que seus correspondentes posicionados fora destas zonas. As feições geoquímicas indicativas destas contaminações, segundo estes autores, são principalmente uma maior oxidação nos magmas, promovendo o decréscimo dos conteúdos de $\mathrm{Fe}_{2} \mathrm{O}_{3}{ }^{\mathrm{T}}$ e $\mathrm{TiO}_{2}$ com a diferenciação, o aumento da proporção de $\mathrm{Al}_{2} \mathrm{O}_{3} /\left(\mathrm{Na}_{2} \mathrm{O}+\right.$ $\mathrm{K}_{2} \mathrm{O}$ ) e a redução nos teores de elementos HFS e ETRP.

Plúton Tismana A assinatura geoquímica das rochas pode ser atribuída a uma derivação de manto litosférico subcontinental enriquecido por metassomatismo relacionado a subducção prévia, conforme sugerido por Duchesne et al. (1998), no entanto o forte enriquecimento em $\mathrm{Zr}, \mathrm{Nb}, \mathrm{TiO}_{2}$, Y e ETR (Fig. 5b) em relação a ASLS sugere contribuição adicional de material astenosférico ou uma menor taxa de fusão mantélica.

Kunlun Esta associação possui características geoquímicas semelhantes com a associação anterior, que podem ser explicadas pelo efeito do metassomatismo relacionado à subducção prévia, conforme sugerido por Williams et al. (2004). O enriquecimento em $\mathrm{Zr}, \mathrm{Nb}$, $\mathrm{TiO}_{2}$, Y e ETR (Fig. 5c) pode ser explicado pela baixa taxa de fusão $(3 \%$ a $4 \%)$ de um flogopita peridotito (Williams et al. 2004) e/ou contribuição adicional de material astenosférico.

Quartzo monzonito Baranadag As rochas possuem um leve enriquecimento em $\mathrm{Rb}$ e $\mathrm{K}_{2} \mathrm{O}$ aliado ao empobrecimento em Ba e Sr (Fig. 5d). Estas feições podem indicar uma pequena contribuição de material crustal nos magmas, conforme sugerido por Ilbeyli et al. (2004). A presença de maiores quantidades de flogopita na fonte mantélica poderia determinar as mesmas feições.

Intrusivas do pós-colisional Svecofenniano do norte da Europa Nestas rochas destacam-se os elevados teores de $\mathrm{Ba}, \mathrm{Sr}, \mathrm{Nb}, \mathrm{Zr}, \mathrm{TiO}_{2}$, Y e ETR (Fig. 5e). Este padrão pode ser atribuído ao efeito do metassomatismo relacionado à subducção prévia, conforme sugerido por Eklund et al. (1998), associado a uma contribuição adicional de material astenosférico. Os padrões geoquímicos dessas rochas são semelhantes aos obtidos nas rochas de Kulun e Tismana destacando-se os conteúdos elevados de $\mathrm{Nb}$ e $\mathrm{TiO}_{2}$ em relação ao padrão da ASLS. No entanto, o enriquecimento em $\mathrm{Ba}$ e Sr pode caracterizar processos geradores do magmatismo shoshonítico próprios de idades arqueanas e paleoproterozóicas. Bitencourt \& Nardi (2004) admitiram que granitóides paleoproterozóicos do sul do Brasil, com várias características da série shoshonítica - alto $\mathrm{Ba}, \mathrm{Sr}$, moderados teores de HFS e ETR, poderiam representar fusões de crosta máfica, deixando resíduos anfibolíticos, em tem- 

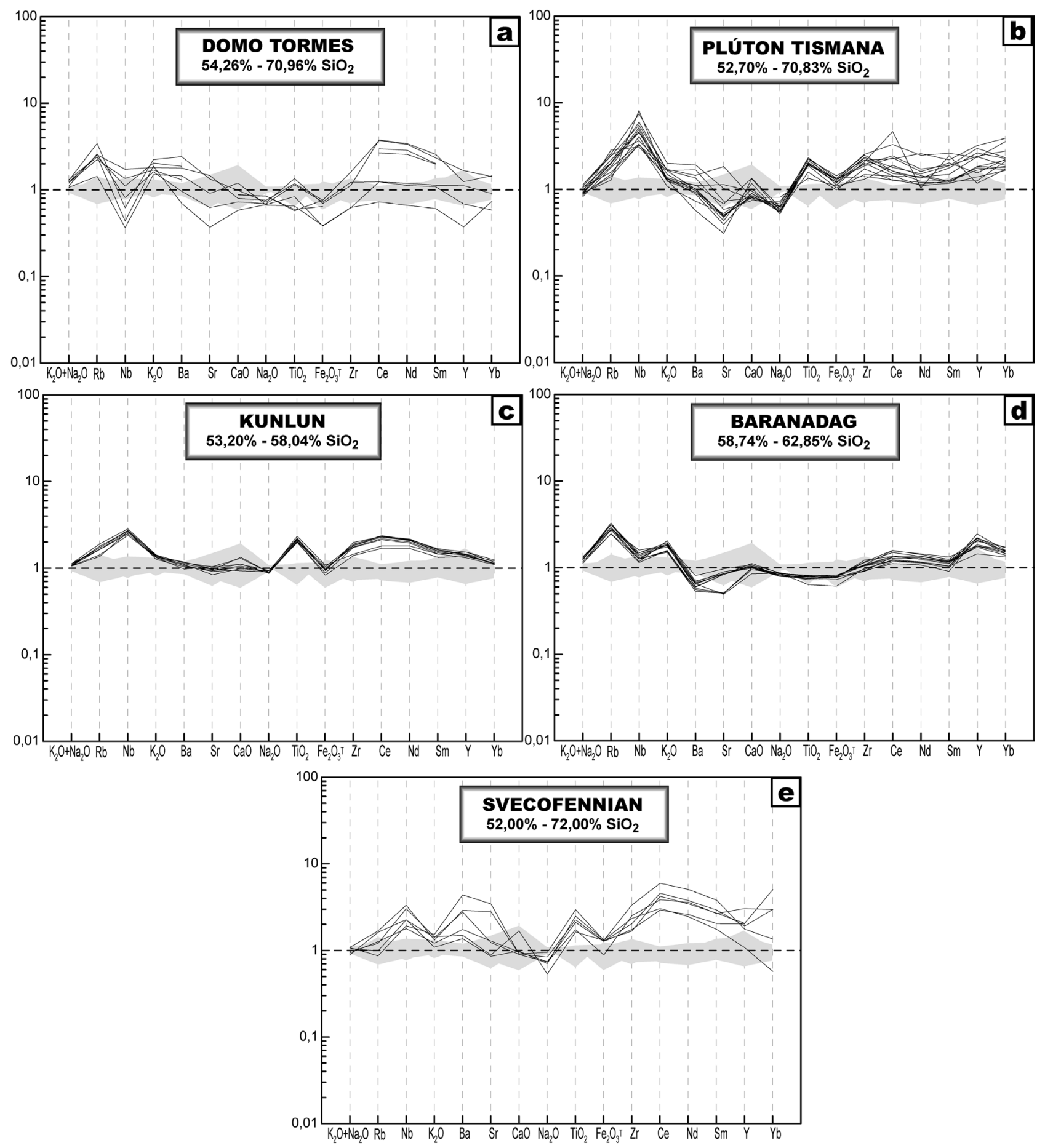

Figura 5 - Diagrama multi-elementos das unidades: Domo Tormes, Plúton Tismana, Kunlun, Baranadag e Svecofennian normalizados pela ASLS.

peraturas da ordem de $900^{\circ} \mathrm{C}$, admissíveis apenas para idades muito antigas.

Os padrões geoquímicos das associações shoshoníticas estudadas apontam para duas tendências geoquímicas distintas. Uma caracterizada pelo enriquecimento em $\mathrm{Zr}, \mathrm{Nb}, \mathrm{TiO}_{2}, \mathrm{Y}$ e ETR, distinta de outra, que é caracterizada pelo aumento dos conteúdos de $\mathrm{Rb}$ e $\mathrm{K}_{2} \mathrm{O}$, das razões $\mathrm{K}_{2} \mathrm{O} / \mathrm{Na}_{2} \mathrm{O}$, pelo decréscimo de $\mathrm{Nb}$ e uma maior variabilidade ou redução nos teores de $\mathrm{Sr}$, $\mathrm{Fe}_{2} \mathrm{O}_{3}{ }_{3}^{\mathrm{T}}, \mathrm{Na}_{2} \mathrm{O}$ e $\mathrm{TiO}_{2}$. Estes padrões geoquímicos são interpretados como decorrentes de uma litosfera mo- dificada por subducção com contribuição de magmas astenosféricos ou com assimilação de materiais crustais respectivamente. Constatou-se que os aumentos dos conteúdos de $\mathrm{Nb}$ expressam razoavelmente a participação de magmas astenosféricos, enquanto que o enriquecimento em $\mathrm{K}_{2} \mathrm{O}$ e $\mathrm{Rb}$ indica assimilação crustal. $\mathrm{O}$ diagrama triangular Nb-Rb- $\mathrm{K}_{2} \mathrm{O}$ (Fig. 6) ilustra a distribuição das diferentes associações shoshoníticas em relação a ASLS, separando o Plúton Tismana, Kunlun e intrusivas do pós-colisional Svecofenniano, cuja origem envolveu contribuição astenosférica, das amostras 


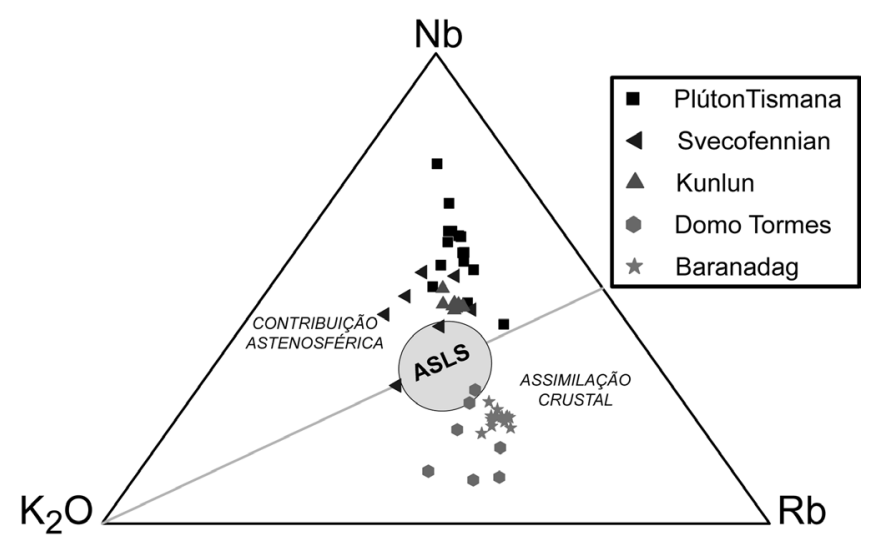

Figura 6 - Diagrama triangular $\mathrm{Nb}-\mathrm{Rb}-\mathrm{K}_{2} \mathrm{O}$ para identificar a contribuição astenosférica versus assimilação crustal nas associações shoshoníticas pós-colisionais estudadas. Os valores de $\mathrm{Nb}$, $\mathrm{Rb}$ e $\mathrm{K}_{2} \mathrm{O}$ das amostras foram normalizados pela ASLS. O círculo em cinza mostra a distribuição das amostras da ASLS.

que apresentam contribuição crustal, representadas pelo Domo Tormes e Quartzo monzonito Baranadag.

CONCLUSÕES O uso da técnica de sliding normalization tem como vantagem a minimização dos efeitos da diferenciação quando comparamos rochas com diferentes graus de diferenciação. Sua aplicação permitiu construir um padrão de normalização com as amostras da ASLS, tendo em vista que esta associação é típica de um ambiente pós-colisional, com ampla variação composicional gerada por cristalização fracionada, derivada de uma fonte litosférica metassomatizada por uma subducção prévia, sem a participação efetiva de assimilação crustal. As demais associações shoshoníticas utilizadas na comparação com a ASLS são também pós-colisonais e derivadas, de acordo com os respectivos autores, da fusão de manto metassomatizado com variável contaminação pela crosta.
Os padrões geoquímicos obtidos com a normalização pela ASLS nas séries escolhidas apresentaram assinaturas que podem ser separadas em um grupo com enriquecimento em $\mathrm{Zr}, \mathrm{Nb}, \mathrm{TiO}_{2}$, $\mathrm{Y}$ e ETR, e outro com enriquecimento em $\mathrm{Rb}$ e $\mathrm{K}_{2} \mathrm{O}$, com razões $\mathrm{K}_{2} \mathrm{O} / \mathrm{Na}_{2} \mathrm{O}$ mais elevadas e uma maior variabilidade ou redução nos teores de $\mathrm{Sr}, \mathrm{Fe}_{2} \mathrm{O}_{3}{ }^{\mathrm{T}}$ e $\mathrm{Na}_{2} \mathrm{O}$. Os padrões geoquímicos observados no primeiro grupo são interpretados como a combinação de uma fonte litosférica metassomatizada por subducção prévia, combinada com a adição de magmas astenosféricos. No segundo grupo admite-se também uma fonte litosférica semelhante, porém com assimilação de materiais crustais e sem evidências de contribuição astenosférica.

$\mathrm{Na}$ investigação das diferentes associações shoshoníticas, o diagrama triangular $\mathrm{Nb}-\mathrm{Rb}-\mathrm{K}_{2} \mathrm{O}$ indica a participação de magmas astenosféricos, na medida em que as amostras se aproximam do vértice do $\mathrm{Nb}$, enquanto que o enriquecimento em $\mathrm{K}_{2} \mathrm{O}$ e $\mathrm{Rb}$ indica assimilação crustal. $\mathrm{O}$ uso deste diagrama permitiu, portanto, separar o Plúton Tismana, Kunlun e intrusivas do pós-colisional Svecofenniano, cuja gênese envolveu contribuição astenosférica, das que apresentam contribuição crustal, representadas pelo Domo Tormes e Quartzo monzonito Baranadag.

A similaridade entre os padrões geoquímicos para associações com idades muito diferentes, pode indicar que as fontes envolvidas na geração do magmatismo shoshonítico têm sido aproximadamente uniformes desde o paleoproterozóico, representado neste trabalho pela associação pós-colisional do Svecofenniano do norte europeu. Esta sugestão, no entanto, deve ser melhor investigada a partir da inclusão de outras associações shoshoníticas paleoproterozóicas.

Agradecimentos Os autores expressam seus agradecimentos ao Programa de Pós-Graduação em Geociências do IG-UFRGS pela infra-estrutura disponibilizada, ao CNPQ pela bolsa de doutorado e de produtividade científica.

\section{Referências}

Bitencourt M.F., Nardi L.V.S. 2000. Tectonic setting and sources of magmatism related to the Southern Brazilian Shear Belt. Revista Brasileira de Geociencias, 30:184187.

Bitencourt M.F. \& Nardi L.V.S. 2004. The role of xenoliths and flow segregation in the genesis and evolution of the Paleoproterozoic Itapema Granite, a crustally derived magma of shoshonitic affinity from southern Brazil. $\mathrm{Li}$ thos, 73:1-19.

Bonin B., Azzouni-Sekkal A., Buss F., Ferrag S. 1998. Alkalic-calcic and alkaline post-orogenic (PO) granite magmatism: petrologic constraints and geodynamic settings. Lithos, 45:45-70.

De La Roche H., Laterrier J., Grandclaude P., Marchal M. 1980. A classification of volcanic and plutonic rocks us- ing $\mathrm{R}_{1} \mathrm{R}_{2}$ diagram and major element analyses - its relationships with current nomenclature. Chemical Geology, 29:183-210.

Duchesne J.C., Berza T., Liégeois J.P., Auwera J.V. 1998. Shoshonitic liquid line of descent from diorite to granite: the Late Precambrian post-collisional Tismana pluton (South Carpathians, Romania). Lithos, 45:281-303.

Eklund O., Konopelko D., Rutanen H., Fröjdö S., Shebanov A.D. 1998. 1.8 Ga Svecofennian post-collisional shoshonitic magmatism in the Fennoscandian shield. Lithos, 45:87-108.

Gastal M.C.P. \& Lafon J.M. 2006.. Reinterpretação do Complexo Intrusivo Lavras do Sul, RS, de acordo com os sistemas vulcano-plutônicos de subsidência. Parte 2: química mineral, geoquímica e isótopos $\mathrm{Pb}-\mathrm{Sr}-\mathrm{Nd}$. Rev. 
Bras. de Geoc., 36(1):125-146.

Gastal M.C.P., Lafon J.M., Ferreira J.F.F., Magro J.F.U., Remus M.V.D., Sommer C.A. 2006. Reinterpretação do Complexo Intrusivo Lavras do Sul, RS, de acordo com os sistemas vulcano-plutônicos de subsidência. Parte 1: geologia, geofísica e geocronologia $(207 \mathrm{~Pb} / 206 \mathrm{~Pb}$ e 206Pb/238U). Rev. Bras. de Geoc., 36(1):109-124.

Harris N.W.B., Pearce J.A., Tindle A.G. 1986. Geochemical characteristics of collision-zone magmatism. In: Coward M.P. \& Ries A.C. (eds.) Collision tectonics. Geological Society of London, Special Paper, 19:115-158.

Ilbeyli N., Pearce J.A., Thirlwall M.F., Mitchell J.G. 2004. Petrogenesis of collision-related plutonics in Central Anatolia, Turkey. Lithos, 72:163-182.

Köksal S., Romer R.L., Göncüoglu M.C., Toksoy-Köksal F. 2004. Timing of post-collisional H-type to A-type granitic magmatism: $\mathrm{U}-\mathrm{Pb}$ titanite ages from the Alpine central Anatolian granitoids (Turkey). Int. J. Earth Sci., 93:974-989.

Le Bas M.J., Le Maitre R.W., Streckeisen A., Zanettin B. 1986. A classification of volcanic rocks based on the total álcalis-silica diagram. J. Petrol., 27:745-750.

Liégeois J.P 1998. Preface - Some words on the post-collisional magmatismo. Lithos, 45:xv-Xvii.

Liégeois J.P., Navez J., Hertogen J., Black R. 1998. Contrasting origin of post-collisional high-K calc-alkaline and shoshonitic versus alkaline and peralkaline granitoids. The use of sliding normalizantion. Lithos, 45:1-28.

Lima E.F. 1995. Petrologia das Rochas Vulcânicas e Hipabissais da Associação Shoshonítica de Lavras do Sul $A S L S, R S$. Tese de Doutoramento, Instituto de Geociências, Universidade Federal do Rio Grande do Sul, 338p.

Lima E.F. \& Nardi L.V.S. 1998. The Lavras do Sul Shoshonitic Association: Implications for Origin and Evolution of Neoproterozoic Shoshonitic Magmatism in Southermost Brazil. J.South American Earth Sciences,11:67-77.

Liz J.D; Lima E.F.; Nardi L.V.S.; Sommer C.A.; Saldanha D.L.; Pierosan R.; Alexandre F.M. 2005. Caracterização geológica e petrologia das rochas monzoníticas da Associação Shoshonítica de Lavras do Sul (RS.). In: Simpósio sobre Vulcanismo e Ambientes Associados, 3, Cabo Frio, Anais, CD-ROOM.

López-Moro F.J. \& López-Plaza M. 2003. Monzonitic series from the Variscan Tormes Dome (Central Iberian Zone): petrogenetic evolution from monzogabro to granite magmas. Lithos, 72:19-44.

López-Plaza M., López-Moro F.J., Gonzalo-Corral J.C., Carnicero A. 1999. Asociaciones de rocas bpasicas e intermédias de afinidad calcoalcalina y shoshonítica y granitóides relacionados em al Domo Hercínicodel Tormes (Salamanca y Zamora). Bol. Soc. Esp. Mineral, 22:211234.

Middlemost E.A.K. 1994. Naming materials in the magma/ igneous rock system. Earth Science Reviews, 37: 215224.

Miller C., Schuster R., Klotzli U., Mair V., Frank W., Purtscheller F. 1999. Post-collisional potassic and ultrapotassic magmatism in SW Tibet : geochemical, Sr-Nd-Pb-O isotopic constraints for mantle source characteristics and petrogenesis. J. Petrol., 40(9):1399-1424.
Molnar P., England P., Martinod J. 1993. Mantle dynamics, uplift of the Tibetan plateau, and the Indian Monsoon. Reviews of Geophysics, 31(4):357-396.

Nardi L.V.S. 1984. Geochemistry and Petrology of the Lavras Granite Complex, RS, Brasil. Tese de Doutoramento, Universidade de Londres, 268p.

Nardi L.V.S. \& Lima E.F. 1985. A Associação Shoshonítica de Lavras do Sul, RS. Rev. Bras. Geol., 15(2):139-146.

Peacock M.A. 1931. Classification of igneous rock series. $J$. Geol., 39:54-67.

Pearce J.A., Bender J.F., De Long S.E., Kidd W.S.F., Low P.J., Guner Y., Saroglu F., Yilmaz Y., Moorbath S., Platt J.P. \& England P.C. 1993. Convective removal of lithosphere beneath mountain belts: Thermal and mechanical consequences. Am. J. Sci., 293:307-336.

Remus M.V.D., Hartmann L.A., Mcnaughton N.J., Groves D.I., Reischl J.L. 2000. Distal magmatic-hydrothermal origin for the Camaquã $\mathrm{Cu}(\mathrm{Au}-\mathrm{Ag})$ and Santa Maria $\mathrm{Pb}, \mathrm{Zn}(\mathrm{Cu}-\mathrm{Ag})$ deposits, southern Brazil. Gondw. Res., 3(2):155-174.

Soliani Jr E., 1986. Os dados geocronológicos do Escudo Sul-rio-grandense e suas implicações de ordem geotectônica.Tese de Doutorado, Universidade de São Paulo, $425 \mathrm{p}$.

Sommer C.A., Lima E.F., Nardi L.V.S., Liz J.D., Waichel B.L. 2006. The evolution of neoproterozoic magmatism in the southernmost Brazil: shoshonitic, high-K tholeitic and silica-satured, sodic alkaline volcanism in the postcollision basin. Anais da Academia Brasileira de Ciências, 78:573-589.

Streckeisen A. 1976. To each plutonic rock its proper name. Earth Science Review, 12:1-33.

Tauson L.V. 1983. Geochemistry and metallogeny of the latitic series. International Geology Review, 25:125135.

Turner S.P., Foden J.D., Morrison R.S. 1992. Derivation of some A-type magmas by fractionation of basaltic magma: an example from the Padthaway ridge, South Australia. Lithos, 28:151-179.

Turner S.P., Hawkesworth C., Liu J., Rogers N., Kelley S., Van Calsteren P. 1993. Timing of Tibetan uplift constrained by analysis of volcanic rocks. Nature, 364:5053.

Turner S.P., Arnaud N., Liu J., Rogers N., Hawkesworth C., Harris N., Kelley S., Van Calsteren P., Deng W. 1996. Postcollision shoshonitic volcanism on the Tibetan Plateau: Implications for convective thinning of the lithosphere and the source of ocean island basalts. J. Petrol., 37:45-71.

Williams H.M., Turner S.P., Pearce J.A., Kelley S.P., Harris N.B.W. 2004. Nature of source regions for post-collisional, potassic magmatism in southern and northern Tibet from geochemical variations and inverse trace element modeling. J. Petrol., 45(3):555-607.

Wilson M. 1993. Magmatic differentiation. J. Geol. Soc. London, 150:611-624.

Manuscrito ID 11019

Submetido em 27 de março de 2008 Aceito em 12 de fevereiro de 2009 